\title{
The Water Supply of Egypt and the Sudan.
}

T $N$ the report recently issued 1 by the Physical Department of Egypt on the discharges and levels of the Nile and the rains of the Nile Basin for Igr9, we have a revival of the reports on the rains of the Nile Basin which, after appearing for eight years, were discontinued on the outbreak of the War.

This report differs from its predecessors in an important respect; the volumes discharged by the Nile and its tributaries now take the first place, and the rainfall measurements form but a minor portion of the volume. This is an indication of the advance which has been made in late years by the Physical Department in the accurate gauging of the Nile supply, a matter of the highest importance both to Egypt and to the Sudan. While formerly most of the determinations were dependent on the accuracy of curves constructed to show the relation between a gauge reading and the corresponding volume of the discharge, we are now presented with no less than 465 measured discharges taken during the year I9I9. Of these 2 Io were on the Blue Nile, 74 on the White Nile, and $\mathrm{r}_{3} 8$ on the main stream. This gives a precision to the results and an authority to the deductions which may be drawn from them that puts the hydrographic work on the Nile on a very high level.

The discharges have been measured with Gurley's pattern of current meter, and these instruments are rated from time to time at Cairo. It has been suggested that discharges measured during the flood are too large in consequence of the meter being affected by the turbulency of the water, but recent experiments by Mr. B. H. Wade show that this effect has been much overestimated.

The characteristics of the Nile regimen are well brought out in the table; the low stage flow of

1 Ministry of Public Works, Egypt. Physical Department. "The Discharges and Levels of the Nile and Rains of the Nile Basin in Igrg." By P. Phillips. Physical Department Paper No. II. (Cairo: Government Publications Office, r924.) P.T.5. only 50 cubic metres per second of the Blue Nile in April, and the rapid rise to 8000 cubic metres per second at the beginning of September, in a year when the Abyssinian rainfall was about 30 per cent. below the average, shows how vast a volume of water pours down to the Sudan and Egypt at this season of the year. There is at this time ample water for the needs of the Sudan in the neighbourhood of the Blue Nile when Egypt is receiving more than its land can possibly utilise.

The discharges of the White Nile show a wholly different type of supply; it varied from about 600 cubic metres per second in April and May to I 300 cubic metres per second in October and November, an increase due to water brought in by the Sobat river, which in IgI9 received an unusually small supply from the southern plateau of Abyssinia.

There are now 48 river gauges on the Nile and its tributaries south of Wadi Halfa which are read regularly, besides 9 on Lakes Victoria, Kioga, and Albert in Uganda.

The rainfall throughout the Nile Basin is presented in a series of tables, and in most places it was below the normal in rgrg. Consequently the level of the lakes on the Lake Plateau of Uganda fell generally; on the Bahrel Jebel the summer rainfall was good, but the extent of marsh in this region prevents the discharge in the lower reaches from gaining by it. The rainfall on the Abyssinian plateau was considerably below the normal, so that the volume passing Wadi Halfa was below the average throughout the year except in July, August, and September; and in November the defect reached 23 per cent.

When we remember that the Nile for the last two thousand miles of its course flows through arid or semi-arid regions, the importance of accurate hydrographical information such as this cannot be overestimated.

\section{Occurrence and Use of Bitumen.}

IN a recent report (No. 625) of the Mines Branch of the Canadian Department of Mines, $\mathrm{Mr}$. Sydney C. Ells contributes a summary account of the nature, mode of occurrence, exploitation, and commercial development of the famous " tar sands" of Northern Alberta, Canada. The report forms an appendix to the author's former " Preliminary Report on the Bituminous Sands of Northern Alberta," No. $28 \mathrm{I}$, published in I9I4, but for some years out of print. The present summary contains the results of further field-survey of the deposits, including examination and sampling of the sands, a résumé of modern methods of recovery of the bitumen from the sand, and some data concerning the laying of demanstration pavements and roadways.

The principal area of exposure of these sands is along the Athabasca River, outcrops occurring for a distance of more than 220 miles. The deposits are probably of Cretaceous age, though the origin of the bitumen is uncertain, a question which, however, is to form the subject of a report already in preparation. The impregnation varies with the texture of the sand, as would be expected, medium and moderately compact deposits being the richest, finely. graded material being the poorest in bitumen content. Attention is directed to the existence of impervious partings or strata within the deposits which act as horizons of concentration of the bitumen from overlying sands, presumably by downward migration.; The more fluid seepages, known as "tar springs," are shown to have originated by lateral migration from sligbtly inclined beds of particularly rich, coarse-grained sand; the author states that such springs are not of commercial value as sources of bitumen, and further, that it is erroneous to regard them as indications of oil-pools, as has been done by certain geologists who have studied this region. The average bitumen content ranges from 20 per cent. to 25 per cent. in the richest deposits, to 15 per cent. in the normal impregnated sands; the crude bituminous sand has a gravity of $x \cdot 75$ and a moisture factor of $\mathrm{r} \cdot 3$ per cent.

The commercial application of this material to paving and road construction must be considered as still being in the experimental stage, though results based on eight years of observation on a highway surfaced in three different ways, namely, with sheet asphalt, bitulithic and bituminous concrete, are certainly encouraging, since at the time of writing the author states that " the pavement [i.e. road surface] was still in first-class condition, and had required no repairs," notwithstanding that heavy traffic included, apart from motor cars, vehicles carrying loads up to ten tons. Crude bituminous sand is not recommended per se as paving material owing to its unbalanced mineral aggregate, lack of uniformity and to freight charges, though it is considered that an attempt should be made to produce an artificial mixture in which the inherent properties and qualities of the sand can be utilised to the greatest advantage. The report concludes with a valuable summary of processes employed for refining bituminous deposits of this character.

NO. 2885 , VOL. I I 5 ] 